\title{
Improved survival rates of AML patients following admission to the intensive care unit.
}

\begin{tabular}{|c|c|}
\hline Journal: & Leukemia and Lymphoma \\
\hline Manuscript ID & GLAL-2018-1189.R1 \\
\hline Manuscript Type: & Original Article - Clinical \\
\hline $\begin{array}{r}\text { Date Submitted by the } \\
\text { Author: }\end{array}$ & $n / a$ \\
\hline Complete List of Authors: & $\begin{array}{l}\text { Fassbind, Priska; University Hospital, Inselspital and University of Bern, } \\
\text { Department of Medical Oncology } \\
\text { Jeker, Barbara; University Hospital, Inselspital and University of Bern, } \\
\text { Department of Medical Oncology } \\
\text { Mueller, Beatrice ; University of Bern, Department of Biomedical } \\
\text { Research } \\
\text { Bacher, Vera Ulrike; Bern University Hospital, University of Bern, } \\
\text { Switzerland, Department of Haematology, Inselspital; Bern University } \\
\text { Hospital, University of Bern, Switzerland, Center of Laboratory Medicine } \\
\text { (ZLM), Inselspital } \\
\text { Zimmerli, Stephan; University Hospital, Inselspital and University of } \\
\text { Bern, Department of Infectious Diseases } \\
\text { Endrich, Olga; University Hospital, Inselspital and University of Bern, } \\
\text { Department of Medicine } \\
\text { Gahl, Brigitta; Clinical Trial Unit Bern, University of Bern } \\
\text { Novak, Urban; University Hospital, Inselspital and University of Bern, } \\
\text { Department of Medical Oncology } \\
\text { Pabst, Thomas; University Hospital, Inselspital and University of Bern, } \\
\text { Department of Medical Oncology }\end{array}$ \\
\hline Keywords: & ICU, intensive care, $A M L$, outcome, mortality \\
\hline
\end{tabular}

\section{SCHOLARONE Manuscripts}




\title{
Improved survival rates of AML patients following admission to the intensive care unit.
}

\section{Original Report}

\begin{abstract}
Authors: ${ }^{1}$ Priska Fassbind, ${ }^{1}$ Barbara Jeker, ${ }^{2}$ Beatrice U. Mueller, ${ }^{3}$ Ulrike Bacher, ${ }^{4}$ Stefan Zimmerli, ${ }^{5}$ Olga Endrich, ${ }^{6}$ Brigitta Gahl, ${ }^{1}$ Urban Novak, ${ }^{1}$ Thomas Pabst.
\end{abstract}

\begin{abstract}
Author affiliations: ${ }^{1}$ Department of Medical Oncology; ${ }^{2}$ Department of Biomedical Research; ${ }^{3}$ Department of Hematology; ${ }^{4}$ Department of Infectious Diseases; ${ }^{5}$ Department of Medicine; and ${ }^{6}$ Clinical Trial Unit Bern; University Hospital Bern, Inselspital; and University of Bern; Switzerland.
\end{abstract}

Manuscript details: 27 pages; 2'908 words (allowed 3'000); summary 150 words (allowed 150); 3 figures; 3 tables; 3 supplemental figures/tables.

Key words: AML; ICU; intensive care; intensive treatment; outcome; prognosis; survival.

Running title: Outcome in AML after ICU admission.

Funding: This work was supported by a grant from the Swiss Cancer League KFS-3795-022016 (to TP).

Corresponding authors: Thomas Pabst, MD; Associate Professor; Department of Medical Oncology; University Hospital; 3010 Berne; Switzerland. phone: +41 3163284 30; fax: +41 3163234 10; E-mail: thomas.pabst@insel.ch 


\begin{abstract}
Induction chemotherapy in AML patients may have life-threatening side effects requiring intensive care unit (ICU) treatment. We analyzed all AML patients receiving intensive chemotherapy at a single academic center between 01/2006-12/2016. At least one ICU admission was observed in $32 \%(76 / 240)$ patients, and $33 \%$ of those died following ICU admission. Whereas the ICU admission proportion remained stable, mortality after ICU admission decreased from $14 \%(2006-2008)$ to $3 \%(2014-2016 ; P=.056)$. The number of failing organ systems inversely correlated with surviving ICU admission $(P<.001)$. Sepsis and renal, cardiac and pulmonary failure were each associated with higher mortality. With increasing ICU duration, survival probability decreased $(P<.001)$, but remained $>50 \%$ even after 14 days of ICU treatment. Progression-free and overall survival were comparable between ICU surviving patients and patients never needing ICU support. In conclusion, outcome after ICU admission of AML patients has substantially improved in recent years.
\end{abstract}




\section{INTRODUCTION}

Intensive chemotherapy with curative intent is standard of care in fit patients with acute myeloid leukemia (AML). Inevitably, this treatment is associated with prolonged immunosuppression and impaired mucocutaneous barriers [1]. Consequently, such patients are prone to infections and frequently require intensive care unit (ICU) support. Previous studies reported that $15-28 \%$ of AML patients need to be admitted to the ICU during induction chemotherapy $[2,3]$, with respiratory failure being the most common indication for admission [4].

Traditionally high mortality rates underlie a restrictive attitude among intensivists to unplanned transfers of hemato-oncologic patients to the ICU [5]. However, perspectives for critically ill cancer patients have substantially improved in recent years and led, together with improved survival rates of patients admitted to general ICUs, to less reluctance to admit AML patients to the ICU [6-9]. Formerly, neutropenic AML patients who developed organ failure were considered to have a poor prognosis; however, the concept that neutropenia is predictive for ICU mortality has paved the way towards a more differentiated approach regarding ICU treatment of AML patients [10]. Accordingly, recent reports have indicated that the need for mechanical ventilation, multi-organ failure, invasive fungal infection, and high illness scores at ICU admission are factors associated with high mortality rates among AML patients $[4,11]$.

In this study, we retrospectively reviewed the medical records of all AML patients receiving intensive chemotherapy at a single academic center between 01/2006 and 12/2016. We analyzed admission proportion to the ICU, assessed outcomes during the study period, and we tested variables associated with mortality in the ICU. Our data support the concept that outcomes of patients with AML after ICU admission have substantially improved in recent years. 


\section{METHODS}

\section{Patients}

In this retrospective analysis, we investigated all consecutive patients with $A M L$ at first diagnosis or at relapse who received intensive chemotherapy with curative intent at the University Hospital of Bern, Switzerland between 01/2006 and 12/2016. Patients with palliative AML treatment or best supportive care were excluded from this analysis. Clinical characteristics of the patients are summarized in Table 1. This study was approved by the local ethics committee of Bern, Switzerland (decision number \#1138/17).

\section{Treatment}

Patients were treated in or according to the SAKK/HOVON-42, $-92,-102,-103$, or -132 protocols. In induction cycle 1 , patients received cytarabine $200 \mathrm{mg} / \mathrm{m}^{2}$ on days $1-7$ and idarubicin $12 \mathrm{mg} / \mathrm{m}^{2}$ on days $1-3$. In induction cycle 2 , cytarabine $1000 \mathrm{mg} / \mathrm{m}^{2} / \mathrm{q} 12 \mathrm{~h}$ on days 1-6 and amsacrine $120 \mathrm{mg} / \mathrm{m}^{2}$ on days 1-3 (until 2012) or daunorubicin $60 \mathrm{mg} / \mathrm{m}^{2}$ on three days (since 2013) were given. For consolidation, patients underwent allogeneic hematopoietic stem cell transplantation, autologous transplantation or a third cycle of consolidation chemotherapy. Allogeneic transplantation was offered to poor-risk patients (with a sibling or an unrelated matched donor) and to intermediate-risk patients (with a sibling matched donor). The remaining patients preferentially received busulfan/cyclophosphamide high-dose chemotherapy and autologous stem cell transplantation or, alternatively, a third conventional chemotherapy cycle with etoposide and mitoxantrone. For relapsing patients, the CLAG-Ida regimen was given consisting of cladribine $5 \mathrm{mg} / \mathrm{m}^{2}$ days $1-5$, cytarabine $2000 \mathrm{mg} / \mathrm{m}^{2}$ days 1 5 and idarubicin $8 \mathrm{mg} / \mathrm{m}^{2}$ days 1-5 [12].

Starting $01 / 2012$, routine antifungal prophylaxis with oral posaconazole was introduced to all patients thereafter. However, no routine antibiotic prophylaxis was applied. Patients received platelet and red cell transfusions when platelets fell below $10 \mathrm{G} / \mathrm{L}$ or if clinically indicated, and 
hemoglobin was below $80 \mathrm{~g} / \mathrm{L}$, respectively. Patients were hospitalized for the entire procedure, and they were discharged after adequate hematologic recovery and physical reconditioning.

\section{Definitions}

Risk assessment was performed according to the European Leukemia Net (ELN) classification, and response criteria were applied according to the International Working Group criteria [30]. Bone marrow examination was scheduled on days 18 and 28 of each induction cycle, and after hematologic recovery following consolidation treatment. Morphologic complete remission (CR) was defined as bone marrow blasts below $5 \%$ together with neutrophil counts exceeding 1.0 $\mathrm{G} / \mathrm{L}$ for three consecutive days and platelet counts above $100 \mathrm{G} / \mathrm{L}$ without transfusions in the three previous days [30]. Complete remission with incomplete hematologic recovery (CRi) was defined as bone marrow blasts below $5 \%$ with neutrophil counts below $1.0 \mathrm{G} / \mathrm{L}$ or platelet counts below $100 \mathrm{G} / \mathrm{L}$.

Progression free survival was calculated from the date of achieving CR1 until disease progression, death or last follow-up (censored Dec 31, 2017), whichever occurred first. Nonrelapsing patients were censored at the last date of follow up (censored Dec 31, 2017). Overall survival was calculated from the date of achieving CR1 until death or last follow-up. Patients still alive or lost to follow-up were censored at the last date when they were known to be alive.

Sepsis in this study was defined in a patient with an infection when two of the following four criteria were identified: temperature $>38.0^{\circ} \mathrm{C}$ or $<36.0^{\circ} \mathrm{C}$; respiratory rate $>20 / \mathrm{min}$ or $\mathrm{PaCO}_{2}$ $<32 \mathrm{mmHg}(<4.3 \mathrm{kPa})$; heart rate $>90 / \mathrm{min}$; and white blood cell $(\mathrm{WBC})$ count $>12 \mathrm{G} / \mathrm{L},<3 \mathrm{G} / \mathrm{L}$, or $>10 \%$ immature neutrophils. SAPS II scores were determined and used according to the criteria defined in the European/North American Multicenter study [31]. Definitions of failing organ systems as used in this analysis are outlined in more detail in supplementary Table S4. 


\section{Statistical Analysis}

Curves depicting progression-free survival (PFS) and overall survival (OS) were estimated using the Kaplan-Meier method and compared between patient groups using the log-rank test. We calculated hazard ratios using Cox regression analysis including ICU admission as time varying explanatory variable, patient age, ELN risk classification, antifungal prophylaxis, year of therapy onset and an interaction term of ICU admission and year as covariates to investigate whether the impact of ICU admission on the hazard remained the same over time. Proportional hazard assumptions were investigated. As only five patients had an undefined ELN risk, these were assigned to the best category in order to allow for ordered categories. We made a sensitivity analysis to check the effect of assigning these patients to the intermediate category and found the same results. Continuous data are presented as median and range, categorical variables as number and percentage, univariate comparisons were done using Fisher's or unpaired t-tests, respectively, and a value of $P<.05$ was considered significant. All Cls and reported $P$ values are two-tailed, and the statistical analysis was performed using GraphPad Prism® Version 6.0 (GraphPad Software, La Jolla, CA) and Stata 14.2 (Stata Corporation, College Station, TX).

\section{RESULTS}

\section{Patient characteristics}

We analyzed 240 consecutive patients with $A M L$ receiving at least one cycle of intensive chemotherapy with curative intent at a single academic center (University Hospital Bern, Switzerland) between $01 / 2006$ and 12/2016. Patients receiving palliative treatment or best supportive care were not included as were patients admitted to the ICU at first diagnosis before initiation of AML treatment. Clinical characteristics of the patients are summarized in Table 1. The median age was 57 years. 
We found that 76 of these $240(32 \%)$ AML patients had to be admitted at least once to the ICU during intensive chemotherapy. The median number of ICU admissions per patient was one (range one to three admissions), and the 76 patients had a total of 92 ICU admissions. All patients were admitted to the same tertiary medico-surgical ICU of the same institution in which AML treatment was performed. No significant differences in clinical characteristics at diagnosis of AML were observed (Table 1 and Supplementary Table S1) between patients with and without ICU admission, and cytogenetic and molecular genetic abnormalities and ELN risk groups were equally balanced.

We found that 25 of the 76 (33\%) patients needing ICU treatment died following ICU admission. The mortality rate of male patients admitted to the ICU was $40 \%$, and it was $21 \%$ for female patients $(P=.085)$. Again, no significant differences in clinical characteristics at diagnosis of AML were observed (Table 1 and Supplementary Table S1) between AML patients with and without ICU admission, and cytogenetic subgroups and ELN risk groups were evenly distributed. Regarding the molecular mutation profiles, NPM1 mutations were more common in the ICU survivor group (29\%; $15 / 51$ patients) compared to patients with fatal outcome after ICU admission (8\%; $2 / 25$ patients; $P=.042)$.

\section{ICU admissions during study period}

The ICU admission rate of all AML patients remained unchanged during the study period with a median of $34 \%$ of all $A M L$ patients admitted at least once to the ICU during intensive AML treatment (Figure 1). Also, the SAPS II scores, median value at ICU admission for all patients was 63 , did not change during the time periods of the study (Figure 1). Whereas 14\% (10/74) of all AML patients being admitted to ICU died in the beginning of the study period (2006 to 2008), this mortality rate dropped to $3 \%(1 / 34$ patients; $P=.056)$ in the last study period (2015 to 2016). Thus, the probability of AML patients to survive ICU treatment increased significantly during the study period.

Factors predicting ICU outcome in AML patients 
Most admissions to the ICU occurred during the first induction cycle (60\%; 55/92 admissions). The mortality rate per ICU admission was similar for induction cycles 1 and 2 and for consolidation (between $20 \%$ and $27 \%$ ), but was higher for relapsing patients receiving reinduction treatment (40\%; 4/10; Table 2). ICU admission occurred at a median of 15 days (range 1 to 69) after start of chemotherapy and 11 days (range 1 to 62) after onset of neutropenia.

The median duration in the ICU was three days (range 1 to 38 ) in the ICU survivor group and six days (range 1 to 19) in the group with fatal outcome. The probability to survive decreased with increasing ICU duration $(P<.001$; Figure 2). The survival probability at the first day after ICU admission was $97 \%$, and it steadily decreased to $68 \%$ if a patient spent 19 or more days in the ICU.

The following clinical conditions were associated with outcome after ICU admission: Patients who died during ICU admission had significantly more often a septic condition (92\%; 23/25 patients compared to $64 \% ; 43 / 67$ patients; $P=.009)$. Also renal failure $(56 \% ; 14 / 25$ versus $30 \% ; 20 / 67$ patients; $P=.029)$, pulmonary failure $(96 \% ; 24 / 25$ versus $57 \% ; 38 / 67 ; P<.001)$ and cardiac decompensation (92\%; $23 / 25$ versus $60 \% ; 40 / 67$ patients; $P=.002$ ) were more common in the group of patients who died following ICU admission. Patients with a fatal outcome after ICU admission had in more than $90 \%$ sepsis, cardiac and pulmonary failure together. Overall, a median of five (range 3 to 9) out of ten assessed failing organ systems were identified in patients dying during ICU treatment, whereas the ICU survivor group had a median of three (range 1 to 8 ) failing organ systems (Table 2). In general, the survival probability dropped $(P<.001)$ with increasing number of failing organ systems, with a survival probability of only $50 \%$ with seven or more failing organ systems (Figure 2).

We also assessed the impact of the need for therapeutic modalities in the ICU on outcome. Mechanical ventilation was needed in $100 \%$ (25/25 patients) of all ICU admissions with lethal outcome compared to $43 \%(29 / 67$ patients $)$ in the ICU survivor group $(P<.001)$. The need for catecholamine support (96\%; $24 / 25$ versus $36 \% ; 24 / 67$ patients; $P<.001)$, dialysis (36\%; 9/25 versus $9 \% ; 6 / 67 ; P=.004$ ) and for AED (automated external defibrillator; $16 \% ; 4 / 25$ versus 
$3 \% ; 2 / 67 ; P=.044)$ was more common in the group with fatal outcome after ICU admission (Table 2).

Finally, Table 3 presents the results of the multivariate analysis. The hazard of disease progression or death decreased by $11 \%$ per year (HR $0.89, \mathrm{Cl} 0.83$ to $0.95, p<0.001$ ), whereas ICU admission did not show an association with this outcome, neither was there an interaction of ICU admission and year of onset of therapy. The hazard of death decreased even by $16 \%$ per year (HR 0.84, Cl 0.78 to $0.9, \mathrm{p}<0.001$ ), while survival after ICU admission did improve, but less than survival in patients who did not need to be admitted to ICU, as indicated by the significant interaction.

\section{Infections and outcome after ICU admission}

We found no differences in incidence and types of bacterial pathogens isolated in AML patients with fatal outcome compared with ICU surviving patients (Supplementary Table S2). Bacterial pathogens were identified in $60 \%$ (15/25 patients) of patients dying following ICU admission which was similar to the group of ICU survivors (57\%; 39/67 patients). Most common identified bacterial pathogens were coagulase-negative staphylococci sp. (16\%; 15/92 patients), enterococcus faecium (14\%; 13/92 patients) and E. coli (21\%; 19/92 patients).

In contrast, fungal infections were more likely in patients with fatal outcome after ICU admission (44\%; $11 / 25$ patients) than in the ICU survivor group $(15 \% ; 10 / 67$ patients; $P=.005)$ (Supplementary Table S2). Importantly, our institution started antifungal prophylaxis by posaconazole in 01/2012 for all AML patients receiving intensive chemotherapy. The effects of this paradigm shift were substantial (Supplementary Table S3). Fungal infections in AML patients needing ICU support dropped from $27 \%$ (16/59 patients) in the study period until $01 / 2012$ to $15 \%$ (5/33 patients) since $01 / 2012$, and we observed no disseminated fungal infections or fungemias in ICU admitted AML patients since then (2012-2017).

\section{Leukemia-specific outcome}


AML patients surviving ICU treatment received less cycles of chemotherapy (Table 4). ICU survivors had to stop AML treatment more often already after one cycle of induction treatment (24\%; $12 / 51$ patients) than never-ICU patients $(7 \% ; 12 / 164$ patients; $P=.004)$. The difference for the second cycle was not significant (31\% versus $24 \%)$. ICU survivors less often had the planned full program of two chemotherapy cycles and one consolidation treatment $(45 \% ; 23 / 51$ patients versus $69 \% ; 113 / 164$ patients; $P=.003$ ).

The frequency of AML relapses was similar in ICU survivors (35\%; $18 / 51$ patients) and neverICU patients (48\%; 78/164), after a median follow-up in ICU survivors of 14.4 months and 20.3 months in never-ICU patients. The PFS was inferior for all patients needing ICU admission (median, 7.7 versus 15.5 months; $P=.005$ ) as was OS (median, 9.2 versus 30.0 months; $P=$ .002; Figure 3). However, when comparing ICU surviving patients with never-ICU patients, differences for PFS (median, 22.3 versus 15.5 months) and for OS (median, 46.5 versus 30.0 months) were no longer significant. 


\section{DISCUSSION}

Intensivists and oncologists face the dilemma of limited resources and, subsequently, must limit ICU admissions to cancer patients with a reasonable probability for recovery. Accordingly, previous studies have indicated that between 25 and $51 \%$ of all oncologic patients requiring ICU treatment are refused at admission $[13,14]$. Nevertheless, ICU survival rates are steadily improving for oncologic patients, and in-hospital survival rates have become similar to those of patients with other severe conditions such as heart disease or liver cirrhosis $[11,15]$. Consequently, refined predictors of ICU survival are an unmet need to characterize those oncologic patients that can benefit most from ICU care.

In this retrospective analysis of 240 consecutive AML patients receiving intensive chemotherapy with curative intent at a single academic center, roughly a third of patients $(n=76 ; 32 \%)$ were admitted to a single tertiary medico-surgical ICU at least once during their planned three cycles of intensive AML treatment; finally, a third of these patients ultimately died following ICU admission ( $n=25 / 76 ; 33 \%)$. These survival rates appear comparable to previous studies of hemato-oncologic patients admitted to the ICU [16-22].

Our study aimed to identify factors associated with favorable outcome following ICU admissions. NPM1 mutations were more common in the ICU survivor group (29\%) as compared to patients with fatal outcome after ICU admission (8\%). This observation raises the hypothesis that patients labeled as "good-risk" - such as AML patients with NPM1 mutations - may have more favorable outcomes even in the case they need intensive care, whereas less favorable genetic AML subtypes have been reported as predictive of poor outcomes following ICU admission [17,18,22].

Our univariate analysis identified several therapeutic modalities associated with unfavorable outcome following ICU admission. Mechanical ventilation was needed in $100 \%$ of all ICU admissions with lethal outcome compared to $43 \%$ in the ICU survivor group $(P<.001)$. This is consistent with a previous study in leukemia patients requiring invasive ventilation, in which intubation was associated with a $17 \%$ increase in mortality [23]. Moreover, invasive ventilation 
is widely described as predictive of mortality in patients with hemato-oncologic malignancies [24-26]. In our study, patients needing invasive ventilation were less likely to survive to ICU discharge than those avoiding intubation. Other ICU treatment modalities associated with fatal ICU outcome were the need for catecholamine support, dialysis and automated external defibrillator.

Patients who died following ICU admission had significantly more often a septic condition. In accordance with this observation, other studies reported that hemato-oncologic patients with septic shock requiring ICU treatment have high mortality rates ranging from 47 to $60 \%[15,26$ 28]. Thus, while outcomes of hemato-oncologic patients with septic shock are improving [29], it appears that this population still has a high risk of mortality in the ICU. Remarkably, we observed no differences in incidence and types of bacterial pathogens isolated in AML patients with fatal outcome compared with ICU surviving patients. In contrast, fungal infections were more likely in patients with fatal outcome after ICU admission. Thus, an obviously important change during the study period at our institution was the introduction of anti-fungal prophylaxis with posaconazole to all $A M L$ patients receiving intensive chemotherapy. The effect of this paradigm shift was substantial, since fungal infections in AML patients needing ICU support dropped from $27 \%$ to $15 \%$, and we observed no disseminated fungal infections or fungemias in ICU admitted AML patients since then. Thus, eliminating a single factor - such as disseminated fungal infections - had a significant effect on the survival probability of critically ill AML patients.

The strengths of this analysis comprise the extensive size of our AML-specific cohort compared to previous studies which assessed outcomes of mixed types of hemato-oncologic patients admitted to the ICU [9]. Limitation of our study was its single center design with no formal ICU admission criteria, potentially resulting in selection and time bias. In addition, quality of life (QOL) and functional status assessments were unavailable.

Finally, our analysis of a large cohort suggests that AML-specific outcome is similar between patients surviving ICU treatment and patients never needing ICU treatment during intensive chemotherapy. In particular, no differences for PFS and for OS were observed between ICU- 
surviving AML patients and never-ICU patients. This finding is remarkable since we observed that AML patients surviving ICU treatment received less cycles of chemotherapy, most likely due to reduced general condition prohibiting further intensive treatment. Whereas larger series of patients may be needed to verify this observation, our data suggest that more AML patients undergoing intensive chemotherapy survive ICU treatment and that the long-term perspective of ICU surviving AML patients is comparable to that of AML patients never needing ICU treatment.

Finally, this analysis demonstrates that the outcomes of AML patients in need of intensive care have substantially improved over the last years. These results may encourage clinicians to consider ICU admission and intensive care treatment for critically ill AML patients during intensive chemotherapy, and they emphasize the need for facilitated access to intensive care for these patients.

\section{CONFLICT OF INTEREST}

The authors declare no conflict of interest.

\section{AUTHORSHIP AND CONTRIBUTION}

PF: performed research and analyzed data; BJ, UN: contributed vital material; YQ, SJ, BM, UB: contributed vital data; BG, OE: analyzed data; and TP: designed research and analyzed data. All authors participated in drafting or reviewing the report and all authors approved the submitted version. 


\section{REFERENCES}

1. Blijlevens NM, Donnelly JP, De Pauw BE. Mucosal barrier injury: biology, pathology, clinical counterparts and consequences of intensive treatment for haematological malignancy: an overview. Bone Marrow Transpl. 2000;25:1269-1278.

2. Schellongowski $P$, Staudinger $T$, Kundi M, et al. Prognostic factors for intensive care unit admission, intensive care outcome, and post-intensive care survival in patients with de novo acute myeloid leukemia: a single center experience. Haematologica. 2011;96:231-237.

3. Atallah E, Cortes J, O'Brien S, et al. Establishment of baseline toxicity expectations with standard frontline chemotherapy in acute myelogenous leukemia. Blood. 2007;110:3547-3551.

4. Bird GT, Farquhar-Smith $\mathrm{P}$, Wigmore $\mathrm{T}$, et al. Outcomes and prognostic factors in patients with haematological malignancy admitted to a specialist cancer intensive care unit: a 5 yr study. Br J Anaesth. 2012;108:452-459.

5. Groeger JS, White P Jr, Nierman DM, et al. Outcome for cancer patients requiring mechanical ventilation. J Clin Oncol. 1999;17:991-997.

6. Bos MM, de Keizer NF, Meynaar IA, et al. Outcomes of cancer patients after unplanned admission to general intensive care units. Acta Oncol. 2012;51:897-905.

7. Moran JL, Solomon PJ, Outcome ACF, Resource Evaluation of the A, New Zealand Intensive Care S. Mortality and intensive care volume in ventilated patients from 1995 to 2009 in the Australian and New Zealand binational adult patient intensive care database. Crit Care Med. 2012;40:800-812.

8. Hill QA. Intensify, resuscitate or palliate: decision making in the critically ill patient with haematological malignancy. Blood Rev. 2010;24:17-25.

9. Azoulay E, Afessa B. The intensive care support of patients with malignancy: do everything that can be done. Intensive Care Med. 2006;32:3-5. 
10. Souza-Dantas VC, Salluh JI, Soares M. Impact of neutropenia on the outcomes of critically ill patients with cancer: a matched case-control study. Ann Oncol. $2011 ; 22: 2094-2100$.

11. Azoulay E, Soares M, Darmon M, et al. Intensive care of the cancer patient: recent achievements and remaining challenges. Ann Intensive Care. 2011;1:5-7.

12. Fridle $\mathrm{C}$, Medinger M, Wilk MC, et al. sCladribine, cytarabine and idarubicin (CLA-lda) salvage chemotherapy in relapsed acute myeloid leukemia (AML). Leuk Lymphoma. 2017;58:1068-1075.

13. Azoulay E, Mokart D, Pene F, et al. Outcomes of critically ill patients with hematologic malignancies: prospective multicenter data from France and Belgium - a groupe de recherche respiratoire en réanimation onco-hématologique study. J Clin Oncol. 2013;31:2810-2818.

14. Thiéry G, Azoulay E, Darmon M, et al. Outcome of cancer patients considered for intensive care unit admission: a hospital-wide prospective study. J Clin Oncol. 2005;23:4406-4413.

15. Azoulay E, Pene F, Darmon M, et al. Groupe de Recherche Respiratoire en Réanimation Onco-Hématologique (Grrr-OH). Managing critically III hematology patients: time to think differently. Blood Rev. 2015;29:359-367.

16. Van Vliet M, Verburg IW, Van Den Boogaard M, et al. Trends in admission prevalence, illness severity and survival of haematological patients treated in Dutch intensive care units. Intensive Care Med. 2014;40:1275-1284.

17. Thakkar SG, Fu AZ, Sweetenham JW, et al. Survival and predictors of outcome in patients with acute leukemia admitted to the intensive care unit. Cancer. 2008;112:2233-2240.

18. Rabbat A, Chaoui D, Montani D, et al. Prognosis of patients with acute myeloid leukaemia admitted to intensive care. Brit J Haemat. 2005;129:350-357. 
19. Lengliné $\mathrm{E}$, Raffoux $\mathrm{E}$, Lemiale $\mathrm{V}$, et al. Intensive care unit management of patients with newly diagnosed acute myeloid leukemia with no organ failure. Leuk Lymphoma. 2012;53:1352-1359.

20. Ferra $C$, Marcos P, Misis $M$, et al. Outcome and prognostic factors in patients with hematologic malignancies admitted to the intensive care unit: a single-center experience. Inter J Hemat. 2007;85:195-202.

21. Magid T, Haase N, Andersen JS, et al. Intensive care of haematological patients. Danish Med J. 2012;59:Article IDA4395.

22. Jackson K, Mollee P, Morris K, et al. Outcomes and prognostic factors for patients with acute myeloid leukemia admitted to the intensive care unit. Leuk Lymphoma. 2014;55:97-104.

23. Price KJ, Cardenas-Turanzas $\mathrm{M}$, Lin $\mathrm{H}$, et al. Prognostic indicators of mortality of mechanically ventilated patients with acute leukemia in a comprehensive cancer center. Minerva Anesthesiologica. 2013;79:147-155.

24. Cornet $A D$, Issa $A I$, van de Loosdrecht $A A$, et al. Sequential organ failure predicts mortality of patients with a haematological malignancy needing intensive care. Europ J Haematol. 2005;74:511-516.

25. Bird GT, Farquhar-Smith P, Wigmore $\mathrm{T}$, et al. Outcomes and prognostic factors in patients with haematological malignancy admitted to a specialist cancer intensive care unit: a 5 yr study. Brit J Anaesthesia. 2012;108:452-459.

26. Namendys-Silva SA, Gonzalez-Herrera MO, Garcia-Guillen FJ, et al. Outcome of critically ill patients with hematological malignancies. Ann Hematol. 2013;92:699-705.

27. Angus DC, van der Poll T. Severe sepsis and septic shock. N Engl J Med. 2013;369:840-851.

28. Park HY, Suh GY, Jeon K, et al. Outcome and prognostic factors of patients with acute leukemia admitted to the intensive care unit for septic shock. Leuk Lymphoma. 2008;49:1929-1934. 
29. Pène F, Percheron S, Lemiale $V$, et al. Temporal changes in management and outcome of septic shock in patients with malignancies in the intensive care unit. Crit Care Med. 2008;36:690-696.

30. Cheson BD, Bennett JM, Kopecky KJ, et al. Revised recommendations of the international Working Group for Diagnosis, Standardization of Response Criteria, Treatment Outcomes, and Reporting Standards for Therapeutic trials in Acute Myeloid Leukemia. J Clin Oncol. 2003;21:4642-4649.

31. Le Gall J-R. Lemeshow S, Saulnier F. A new Simplified Acute Physiology Score (SAPS II) Based on a European/North American Multicenter Study. JAMA. 1993;270:29572963. 


\section{FIGURE LEGENDS}

Figure 1: ICU admission rate, ICU mortality rate and SAPS II scores during the study period. (A) Depicted is the proportion of AML patients receiving intensive chemotherapy which were admitted to the ICU during the various periods of the study. (B) The mortality rate is shown of all patients receiving intensive chemotherapy during the study periods. (C) The median of SAPS II scores is demonstrated of all ICU patients during the various periods of the study.

Figure 2: Survival probability depending on duration and number of organ system failures during ICU. (A) The survival probability of AML patients is summarized admitted to the ICU depending on duration of ICU treatment. (B) The survival probability of AML patients admitted to the ICU is demonstrated depending on the number of failing organ systems.

Figure 3: Progression-free (PFS) and overall survival (OS). (A) PFS and (B) OS of AML patients never needing ICU treatment compared to patients needing ICU treatment at least once during intensive chemotherapy treatment. (C) PFS and (B) OS of AML patients surviving ICU treatment compared to patients never needing ICU treatment. 


\section{Figure 1}

A)

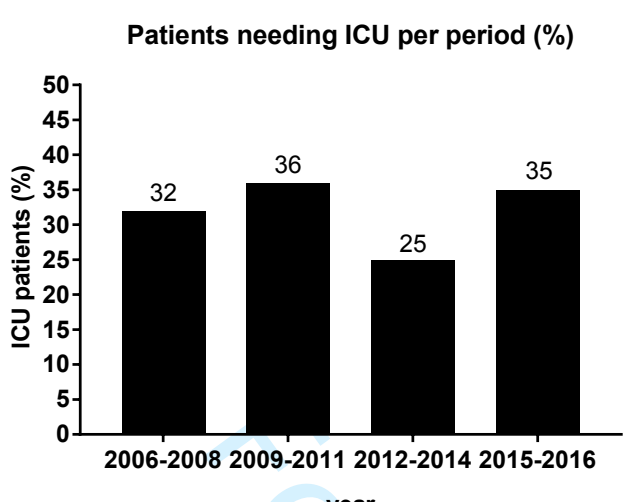$$
\text { all }
$$

non ICU patients ICU patients

$\begin{array}{lll}64 & 68 & 34 \\ 41 & 51 & 22 \\ 23 & 17 & 12\end{array}$

B)

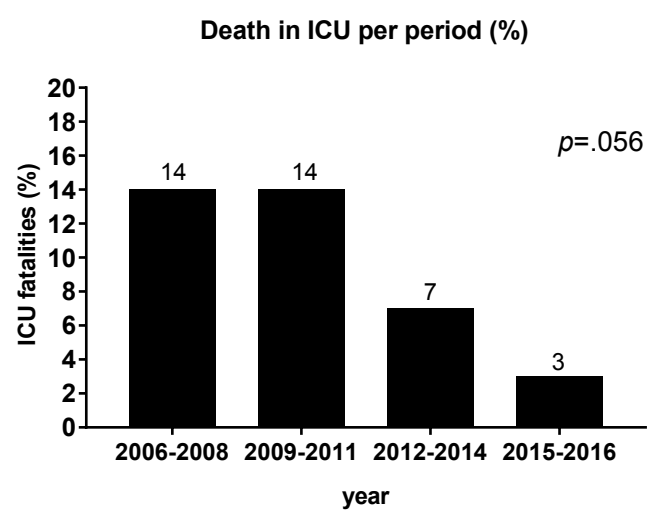

all
ICU fatalities

Median SAPS II score per period

C)

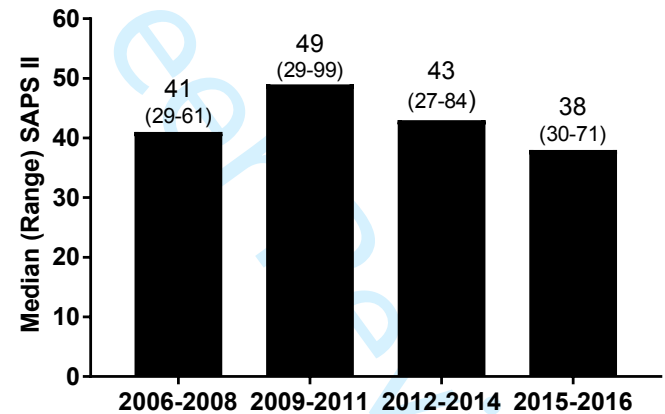

ICU patients $\quad 24 \quad 23^{\text {year }} 17 \quad 17$ 


\section{Figure 2}

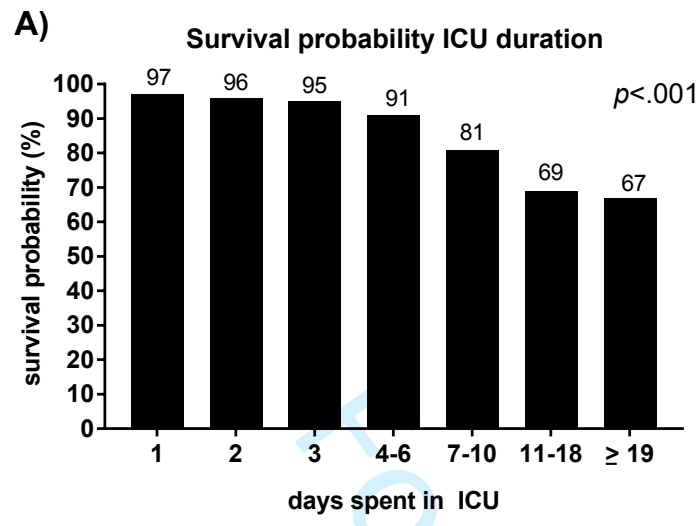

B) Survival probability organ system failure

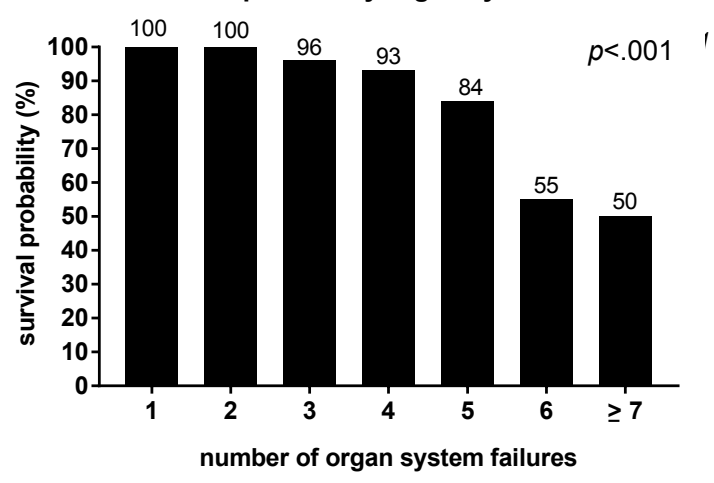

20 
Page 21 of 29

Leukemia and Lymphoma

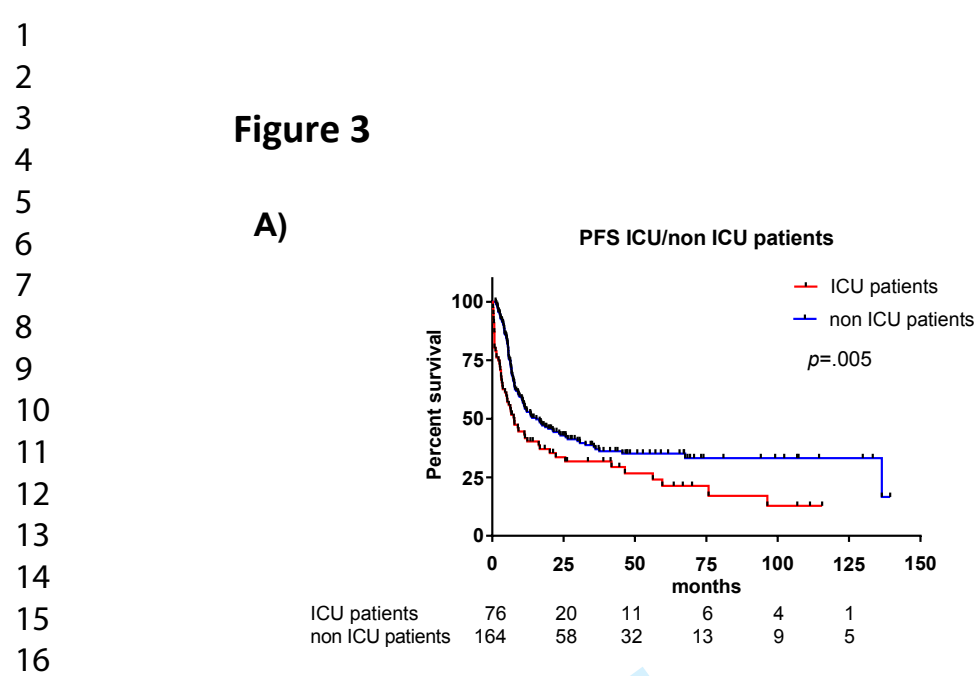

17

18

19

20

21

22

23

24

25

26

27

28

29

30

31

32

33

34

35

36

37

38

39

40

41

42

43

44

45

46

47

48

49

50

51

52

53

54

55

56

57

58

59

60

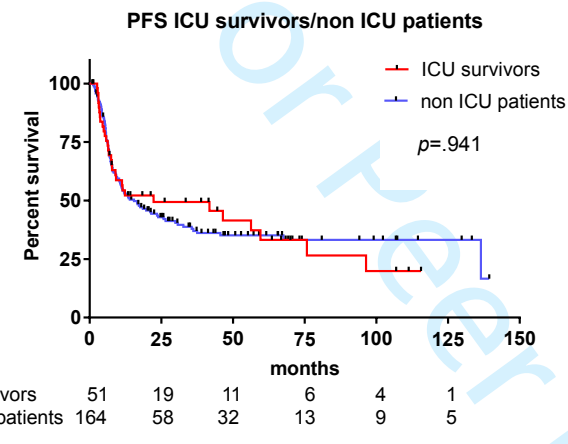
non ICU patients 164
ICU survivors

k)

C)
B)

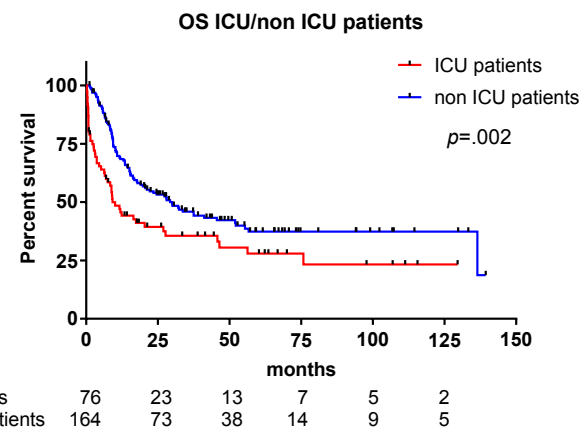

D)

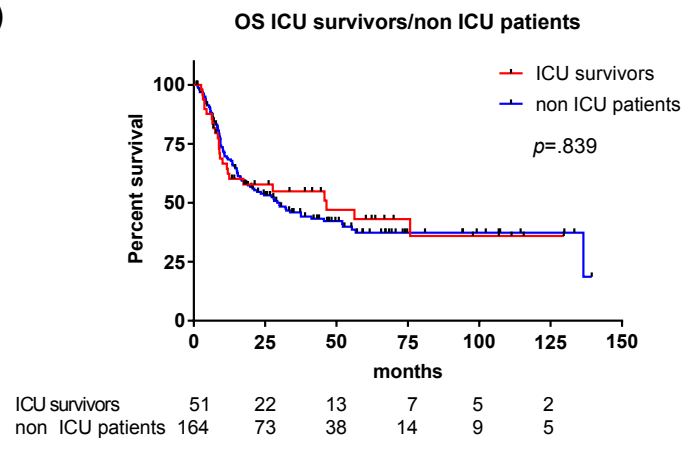

CU patients

non ICU patients
8

Fassbind et al

URL: http://mc.manuscriptcentral.com/glal Outcome in AML after ICU admission. 
Table 1: Demographic features, laboratory parameters and characteristics of the AML in all patients admitted to ICU versus those that never require ICU care, and in patients with fatal outcomes versus those surviving the ICU period.

\begin{tabular}{|c|c|c|c|c|c|c|c|c|c|c|}
\hline \multirow{2}{*}{$\begin{array}{l}\text { Parameter } \\
\text { Male/female, n }\end{array}$} & \multicolumn{2}{|c|}{$\begin{array}{l}\text { all ICU patients } \\
\quad(n=76)\end{array}$} & \multicolumn{2}{|c|}{$\begin{array}{l}\text { never-ICU patients } \\
\qquad(n=164)\end{array}$} & \multirow{2}{*}{$\begin{array}{l}\boldsymbol{p} \\
\mathrm{ns}\end{array}$} & \multicolumn{2}{|c|}{$\begin{array}{l}\text { fatal ICU outcome } \\
\qquad(n=25)\end{array}$} & \multicolumn{2}{|c|}{$\begin{array}{l}\text { ICU survivors } \\
\quad(n=51)\end{array}$} & \multirow{2}{*}{$\begin{array}{l}p \\
\mathrm{~ns}\end{array}$} \\
\hline & & /29 & & $86 / 78$ & & 19 & & & 23 & \\
\hline Age at diagnosis & 57 & & 57 & & ns & 57 & & 57 & & \\
\hline ELN risk; favorable, $\mathrm{n}(\%)$ & 24 & $(32)$ & 55 & (33) & ns & 7 & $(28)$ & 17 & (33) & ns \\
\hline intermediate, $\mathrm{n}(\%)$ & 18 & $(24)$ & 36 & $(22)$ & ns & 6 & $(24)$ & 12 & $(24)$ & ns \\
\hline adverse, $\mathrm{n}(\%)$ & 32 & $(42)$ & 70 & (43) & ns & 11 & (44) & 21 & (41) & ns \\
\hline ND, $\mathrm{n}(\%)$ & 2 & $(2)$ & 3 & $(2)$ & ns & 1 & $(4)$ & 1 & $(2)$ & ns \\
\hline \multicolumn{11}{|l|}{ Molecular mutations: } \\
\hline CEBPA, $\mathrm{n}(\%)$ & 3 & (4) & 4 & $(2)$ & ns & 0 & (0) & 3 & $(6)$ & ns \\
\hline NPM1, $\mathrm{n}(\%)$ & 17 & $(22)$ & 39 & $(24)$ & ns & 2 & $(8)$ & 15 & (29) & .042 \\
\hline FLT3-ITD/-TKD, n (\%) & 13 & (17) & 36 & (22) & ns & 4 & (16) & 9 & (18) & ns \\
\hline WBC, G/L, median (range) & 8.6 & $(0.4-575)$ & 6.4 & $(0.5-270)$ & ns & 13.4 & $(0.4-181)$ & 8.2 & $(0.9-575)$ & ns \\
\hline LDH, IU/L, median (range) & 637 & $(213-2858)$ & 697 & $(117-5154)$ & ns & 632 & $273-2291$ & 637 & $(213-2858)$ & ns \\
\hline Bone marrow blasts, $\%$, median & 70 & & 70 & & ns & 70 & & 70 & & ns \\
\hline Peripheral blasts, \%, median & 25 & & 33.5 & & ns & 22.5 & & 28.5 & & ns \\
\hline
\end{tabular}

ICU: intensive care unit; ELN: European Leukemia Net risk classification; ND: risk classification was not possible due to missing cytogenetic and/or molecular analysis; WBC: white blood cells; LDH: lactate dehydrogenase with upper normal level $<480$ IU/L; median values are given whereas not otherwise indicated. 
Table 2: ICU admissions, organs systems involved and ICU interventions in patients with fatal outcomes versus patients surviving the ICU period.

\begin{tabular}{|c|c|c|c|c|c|}
\hline \multirow{2}{*}{$\begin{array}{l}\text { Parameter } \\
\text { ICU admission in cycle } 1, \mathrm{n}(\%)\end{array}$} & \multicolumn{2}{|c|}{$\begin{array}{l}\text { Deaths in ICU } \\
(n=25 ; 27.2 \%)\end{array}$} & \multicolumn{2}{|c|}{$\begin{array}{l}\text { ICU survivors } \\
\text { (n=67; } 72.8 \%)\end{array}$} & \multirow{2}{*}{$\begin{array}{c}\begin{array}{c}p \\
\text { values }\end{array} \\
\mathrm{ns}\end{array}$} \\
\hline & 14 & (56) & 41 & (61) & \\
\hline cycle $2, \mathrm{n}(\%)$ & 6 & (24) & 16 & (24) & ns \\
\hline cycle 3, n (\%) & 1 & (4) & 4 & (6) & ns \\
\hline re-induction, $\mathrm{n}(\%)$ & 4 & $(16)$ & 6 & (9) & ns \\
\hline Mortality rate in cycle $1, \mathrm{n}(\%)$ & \multicolumn{4}{|c|}{$14 / 55(26)$} & \\
\hline cycle 2, n (\%) & \multicolumn{4}{|c|}{$6 / 22(27)$} & \\
\hline cycle 3, n (\%) & \multicolumn{4}{|c|}{$1 / 5 \quad(20)$} & \\
\hline re-induction, n (\%) & \multicolumn{4}{|c|}{$4 / 10(40)$} & \\
\hline \multicolumn{6}{|l|}{ ICU admission, after onset of: } \\
\hline chemotherapy, day, (range) & 12 & $(4-23)$ & 15 & $(1-69)$ & ns \\
\hline neutropenia, day, (range) & 11 & $(2-36)$ & 11 & $(1-62)$ & ns \\
\hline ICU duration, days, median (range) & 6 & $(1-19)$ & 3 & $(1-38)$ & ns \\
\hline \multicolumn{6}{|l|}{ Failing organ systems: } \\
\hline sepsis, $\mathrm{n}(\%)$ & 23 & (92) & 43 & (64) & .009 \\
\hline renal, n (\%) & 14 & (56) & 20 & (30) & .029 \\
\hline pulmonary, n (\%) & 24 & (96) & 38 & (57) & $<.001$ \\
\hline cardiac, $\mathrm{n}(\%)$ & 23 & (92) & 40 & (60) & .002 \\
\hline DIC, $\mathrm{n}(\%)$ & 6 & (24) & 10 & (15) & Ns \\
\hline CNS, n (\%) & 9 & (36) & 23 & (34) & Ns \\
\hline colitis, $\mathrm{n}(\%)$ & 13 & $(52)$ & 24 & (36) & Ns \\
\hline paralytic ileus, n (\%) & 5 & (20) & 4 & (6) & Ns \\
\hline Bleeding, $n(\%)$ & 13 & (52) & 22 & (33) & Ns \\
\hline hepatic, n (\%) & 5 & (20) & 6 & (9) & Ns \\
\hline Number of failing organ systems, (range) & 5 & $(3-9)$ & 3 & $(1-8)$ & $<.001$ \\
\hline \multicolumn{6}{|l|}{ Interventions during ICU stay: } \\
\hline mechanical ventilation , $\mathrm{n}(\%)$ & 25 & $(100)$ & 29 & (43) & $<.001$ \\
\hline duration, days, (range) & 4 & $(1-16)$ & 3 & $(3-34)$ & ns \\
\hline catecholamines, $\mathrm{n}(\%)$ & 24 & (96) & 24 & $(36)$ & $<.001$ \\
\hline antibiotics, $\mathrm{n}(\%)$ & 25 & $(100)$ & 67 & $(100)$ & ns \\
\hline dialysis, $\mathrm{n}(\%)$ & 9 & (36) & 6 & (9) & .004 \\
\hline AED, $n(\%)$ & 4 & (16) & 2 & (3) & .044 \\
\hline \multicolumn{6}{|l|}{ Patients with failing organ systems: } \\
\hline 1 system, $n(\%)$ & 0 & (0) & 9 & (13) & Ns \\
\hline 2 systems, n (\%) & 0 & (0) & 11 & (16) & .032 \\
\hline 3 systems, n (\%) & 3 & (16) & 16 & (24) & .022 \\
\hline 4 systems, n (\%) & 4 & (16) & 18 & (27) & .004 \\
\hline 5 systems, n (\%) & 6 & (24) & 4 & (6) & $\mathrm{Ns}$ \\
\hline 6 systems, n (\%) & 9 & (36) & 6 & (9) & Ns \\
\hline 7 systems, n (\%) & 0 & (0) & 2 & (3) & Ns \\
\hline 8 systems, n (\%) & 1 & (4) & 1 & (2) & Ns \\
\hline 9 systems, n (\%) & 2 & (8) & 0 & (0) & Ns \\
\hline
\end{tabular}

ICU: intensive care unit; median values are given whereas not otherwise indicated; bleeding events comprised: intestinal: 6 (24\%) vs 14 (21\%); intracranial: 3 (12\%) vs $4(6 \%)$, pulmonary: 4 (16\%) vs $1(2 \% ; p=0.0183)$; others $1(4 \%)$ vs $3(5 \%)$; DIC: disseminated coagulopathy; dialysis: extrarenal therapy; CNS: central nervous system; AED: automated external defibrillator. 
Table 3: Multivariable predictors of disease progression and of death.

\begin{tabular}{|c|c|c|c|c|}
\hline \multirow[b]{3}{*}{ Full model } & \multicolumn{2}{|c|}{ Disease Progression } & \multicolumn{2}{|l|}{ Death } \\
\hline & $\begin{array}{l}\text { Hazard ratio }(95 \% \\
\mathrm{Cl})\end{array}$ & $p$ & $\begin{array}{l}\text { Hazard ratio }(95 \% \\
\mathrm{Cl})\end{array}$ & $p$ \\
\hline & & & & \\
\hline ICU & 1.81 (1.12 to 2.92$)$ & 0.015 & 2.68 (1.64 to 4.37$)$ & $<0.001$ \\
\hline Year (centered, per year) & $0.90(0.84$ to 0.96$)$ & 0.002 & 0.85 (0.79 to 0.92$)$ & $<0.001$ \\
\hline ICU x year & $1.06(0.91$ to 1.23$)$ & 0.452 & $1.17(1.00$ to 1.38$)$ & 0.051 \\
\hline Age (per 10 years) & $1.18(1.03$ to 1.36$)$ & 0.021 & $1.22(1.04$ to 1.42$)$ & 0.012 \\
\hline ELN risk & $1.64(1.35$ to 2.00$)$ & $<0.001$ & 1.69 (1.37 to 2.08$)$ & $<0.001$ \\
\hline Antifungal prophylaxis & $0.99(0.41$ to 2.35$)$ & 0.973 & $0.82(0.32$ to 2.09$)$ & 0.683 \\
\hline Specific contrasts & & & & \\
\hline Effect of ICU in 2006 & 1.36 (0.73 to 2.52$)$ & 0.336 & 1.21 (0.64 to 2.29$)$ & 0.564 \\
\hline Effect of ICU in 2011 & 1.81 (1.12 to 2.92$)$ & 0.015 & 2.68 (1.64 to 4.37$)$ & $<0.001$ \\
\hline Effect of ICU in 2016 & 2.41 (0.81 to 7.23$)$ & 0.116 & $5.93(1.85$ to 18.96$)$ & 0.003 \\
\hline $\begin{array}{l}\text { Effect of year in patients not admitted to } \\
\text { ICU }\end{array}$ & $0.90(0.84$ to 0.96$)$ & 0.002 & $0.85(0.79$ to 0.92$)$ & $<0.001$ \\
\hline Effect of year in patients admitted to ICU & 0.95 (0.83 to 1.10$)$ & 0.493 & $1.00(0.86$ to 1.15$)$ & 0.967 \\
\hline
\end{tabular}

ICU, intensive care unit. ELN, European Leukemia Net. 
ICU: intensive care unit; median values are given whereas not otherwise indicated; PFS: progression-free survival; OS: overall survival.

\begin{tabular}{|c|c|c|c|c|c|}
\hline \multirow{2}{*}{$\begin{array}{l}\text { Parameter } \\
\text { Only one induction cycle received, n (\%) }\end{array}$} & \multicolumn{2}{|c|}{$\begin{array}{l}\text { ICU survivors } \\
\quad(n=51)\end{array}$} & \multicolumn{2}{|c|}{$\begin{array}{c}\text { never-ICU } \\
(n=164)\end{array}$} & \multirow{2}{*}{$\begin{array}{c}p \\
\text { values } \\
.004\end{array}$} \\
\hline & 12 & (24) & 12 & (7) & \\
\hline Two induction cycles received, $\mathrm{n}(\%)$ & 16 & (31) & 39 & (24) & Ns \\
\hline Three cycles including consolidation with: $\mathrm{n}(\%)$ & 23 & (45) & 113 & (69) & .003 \\
\hline conventional chemotherapy, $\mathrm{n}(\%)$ & 3 & $(6)$ & 18 & (11) & ns \\
\hline autologous transplantation, $\mathrm{n}(\%)$ & 17 & (33) & 79 & (48) & ns \\
\hline allogeneic transplantation, $\mathrm{n}(\%)$ & 3 & $(6)$ & 16 & (10) & ns \\
\hline Relapse, $\mathrm{n}(\%)$ & 18 & $(35)$ & 78 & $(48)$ & ns \\
\hline time since diagnosis, in days, median (range) & 233 & $(86-2895)$ & 231 & $(64-2031)$ & ns \\
\hline Mortalities, $\mathrm{n}(\%)$ & 25 & (49) & 91 & (56) & ns \\
\hline Median follow up; months (range) & 14.4 & $(1.4-127.8)$ & 20.3 & $(1.3-138)$ & ns \\
\hline 5 year PFS, $n(\%)$ & 9 & (18) & 25 & (15) & ns \\
\hline 5 year OS, $\mathrm{n}(\%)$ & 11 & (22) & 27 & (17) & ns \\
\hline
\end{tabular}

Table 4: AML treatments and clinical outcomes in ICU survivors versus patients never needing ICU care. 
Supplementary Table S1: Cytogenetic abnormalities and FAB subtypes at diagnosis of AML.

\begin{tabular}{|c|c|c|c|c|c|c|}
\hline Parameter & $\begin{array}{c}\text { all ICU } \\
\text { patients } \\
(n=76)\end{array}$ & $\begin{array}{c}\text { never-ICU } \\
(n=164)\end{array}$ & $\begin{array}{c}p \\
\text { values }\end{array}$ & $\begin{array}{c}\text { fatal ICU } \\
\text { outcome }(n=25)\end{array}$ & $\begin{array}{l}\text { ICU survivors } \\
\qquad(n=51)\end{array}$ & $\begin{array}{c}p \\
\text { values }\end{array}$ \\
\hline \multicolumn{5}{|l|}{ Cytogenetic abnormalities: } & & \\
\hline $\mathrm{t}(15 ; 17), \mathrm{n}(\%)$ & $4 \quad(5)$ & $8 \quad(5)$ & ns & $(12)$ & $1 \quad(2)$ & ns \\
\hline $\mathrm{t}(8 / 21), \mathrm{n}(\%)$ & (7) & (8) & ns & (8) & $316)$ & ns \\
\hline $\operatorname{inv}(16), \mathrm{n}(\%)$ & $3 \quad(4)$ & $6 \quad(4)$ & ns & (8) & $(2)$ & ns \\
\hline trisomy $11, \mathrm{n}(\%)$ & $1 \quad(1)$ & (1) & ns & (0) & (2) & ns \\
\hline deletion $7, \mathrm{n}(\%)$ & $9 \quad(12)$ & $13 \quad(8)$ & ns & (8) & (14) & ns \\
\hline trisomy $8, \mathrm{n}(\%)$ & $7 \quad(9)$ & $9 \quad(6)$ & ns & (0) & (14) & ns \\
\hline \multicolumn{7}{|l|}{ AML (FAB) classification: } \\
\hline $\mathrm{MO}, \mathrm{n}(\%)$ & $(16)$ & $23 \quad(13)$ & ns & (16) & (16) & ns \\
\hline $\mathrm{M} 1, \mathrm{n}(\%)$ & (20) & (17) & ns & (12) & $(22)$ & ns \\
\hline $\mathrm{M} 2, \mathrm{n}(\%)$ & $20 \quad(26)$ & $41 \quad(25)$ & ns & (24) & $(28)$ & ns \\
\hline M3, n (\%) & $4 \quad(5)$ & $(6)$ & ns & (12) & $(2)$ & ns \\
\hline M4, n (\%) & $9 \quad(12)$ & (13) & ns & (20) & (8) & ns \\
\hline M5, n (\%) & 6 (8) & (14) & ns & (4) & (10) & ns \\
\hline M6, n (\%) & $1 \quad(1)$ & $7 \quad(4)$ & ns & (0) & $(2)$ & ns \\
\hline M7, n (\%) & (0) & 1 (1) & ns & (0) & (0) & ns \\
\hline $\mathrm{ND}, \mathrm{n}(\%)$ & (12) & (7) & ns & (12) & (12) & ns \\
\hline
\end{tabular}

ICU: intensive care unit; FAB: French-American-British classification; ND: FAB classification not possible. 
Supplementary Table S2: Infectious pathogens identified in ICU patients.

\begin{tabular}{|c|c|c|c|c|c|}
\hline \multirow{2}{*}{$\begin{array}{l}\text { Parameter } \\
\text { Fungal infections, n (\%) }\end{array}$} & \multicolumn{2}{|c|}{$\begin{array}{l}\text { fatal ICU outcome } \\
\qquad(n=25)\end{array}$} & \multicolumn{2}{|c|}{$\begin{array}{l}\text { ICU survivors } \\
\quad(n=67)\end{array}$} & \multirow{2}{*}{$\begin{array}{c}\begin{array}{c}p \\
\text { values }\end{array} \\
.005 \\
\end{array}$} \\
\hline & 11 & (44) & 10 & (15) & \\
\hline Candida albicans, n (\%) & 5 & (20) & 2 & (3) & .014 \\
\hline other Candida (lusitaniae, dubliniensis), n (\%) & 2 & (8) & 0 & (0) & ns \\
\hline Aspergillus spp., $n(\%)$ & 2 & (8) & 3 & (4) & ns \\
\hline others (yeast, mould), n (\%) & 4 & $(16)$ & 0 & (0) & .004 \\
\hline ND fungal infections (CT), $\mathrm{n}(\%)$ & 2 & (8) & 5 & (7) & ns \\
\hline Bacterial infections, n (\%) & 15 & $(60)$ & 39 & (57) & ns \\
\hline Bacillus cereus, $\mathrm{n}(\%)$ & 1 & (4) & 3 & (4) & ns \\
\hline Pseudomonas aeruginosa, $\mathrm{n}(\%)$ & 1 & (4) & 2 & (3) & ns \\
\hline Pseudomonas spp, n (\%) & 1 & (4) & 0 & (0) & ns \\
\hline MRSA (staphylococcus aureus), n (\%) & 0 & (0) & 3 & (4) & ns \\
\hline Enterococcus faecium, $\mathrm{n}(\%)$ & 5 & (20) & 8 & (12) & ns \\
\hline other Enterococcus spp, n (\%) & 0 & $(0)$ & 1 & $(2)$ & ns \\
\hline Enterobacter cloacae, $\mathrm{n}(\%)$ & 2 & (8) & 1 & $(2)$ & ns \\
\hline Staphylococcus coagulase-negative (SCN), n (\%) & 3 & $(12)$ & 12 & (18) & ns \\
\hline E. coli, $n(\%)$ & 3 & (12) & 16 & (24) & ns \\
\hline Klebsiella pneumoniae, $\mathrm{n}(\%)$ & 1 & (4) & 4 & (6) & ns \\
\hline Klebsiella oxytoca, n (\%) & 1 & (4) & 3 & (4) & ns \\
\hline Clostridium difficile (fecal positive), $\mathrm{n}(\%)$ & 2 & (8) & 2 & (3) & ns \\
\hline others $*, n(\%)$ & 1 & (4) & 9 & (13) & ns \\
\hline
\end{tabular}

*others: Streptococcus viridans ( $n=4)$; Bacillus thuringiensis ( $n=2)$; Mycobacterium spp. $(n=1)$; Stenotrophomonas maltophilia $(n=1)$; Citrobacter sp ( $n=1)$; Cocci sp. ND ( $n=1)$; multiple infections can be listed in single patients; ND: not determined; ICU: intensive care unit. 
Supplementary Table S3: Fungal infections depending on study period.

\begin{tabular}{|c|c|c|c|}
\hline Parameter & $\begin{array}{c}\text { no posaconazole } \\
\text { prophylaxis } \\
<2012 ; n=59\end{array}$ & $\begin{array}{c}\text { with } \\
\text { posaconazole } \\
\text { prophylaxis } \\
\geq 2012 ; n=33\end{array}$ & $\begin{array}{c}P \\
\text { values }\end{array}$ \\
\hline Fungal infections: total, $\mathrm{n}(\%)$ & $16 / 59 \quad(27)$ & $5 / 33 \quad(15)$ & ns \\
\hline in ICU patients with fatal outcome, $\mathrm{n}(\%)$ & $11 / 21$ & $0 / 4$ & ns \\
\hline in patients surviving ICU admissions, $\mathrm{n}(\%)$ & $5 / 38$ & $5 / 29$ & ns \\
\hline \multicolumn{4}{|l|}{ Disseminated fungal infections/fungemia: } \\
\hline in ICU patients with fatal outcome, $\mathrm{n}(\%)$ & 4 & 0 & ns \\
\hline in patients surviving ICU admissions, $\mathrm{n}(\%)$ & 4 & 0 & ns \\
\hline
\end{tabular}

ICU: intensive care unit; ns: not significant. 
Supplementary Table S4: Definitions of failing organ systems as used in this analysis.

\begin{tabular}{|c|c|}
\hline Failing organ system & \\
\hline sepsis & $\begin{array}{l}\text { 2 out of the } 4 \text { following points: } \\
\text { 1. temperature }>38.0^{\circ} \mathrm{C} \text { or }<36.0^{\circ} \mathrm{C} \\
\text { 2. respiratory rate }>20 / \mathrm{min} \text { or } \mathrm{PaCO}_{2}<32 \mathrm{mmHg}(<4.3 \mathrm{kPa}) \\
\text { 3. heart rate }>90 / \mathrm{min} \\
\text { 4. white blood cell (WBC) count }>12 \mathrm{G} / \mathrm{L},<3 \mathrm{G} / \mathrm{L} \text {, or }>10 \% \text { immature neutrophils } \\
\text { qSOFA: } 2 \text { of the following points: } \\
\text { - respiratory rate } \geq 22 / \mathrm{min} \\
\text { - GCS }>15 \\
\text { - systolic } \mathrm{BP} \leq 100 \mathrm{mmHg}\end{array}$ \\
\hline renal & $\begin{array}{l}\text { - increase in the serum creatinine value of } 0.3 \mathrm{mg} / \mathrm{dl} \text { within } 48 \text { hours } \\
\text { - or a } 1.5-1.9 \text {-fold increase of the serum creatinine value within } 7 \text { days } \\
\text { - or an urine production of }<0.5 \mathrm{ml} / \mathrm{kg} \text { body weight/h during } 6 \text { hours }\end{array}$ \\
\hline pulmonary & $\begin{array}{l}\text { arterial blood gas analysis: } \\
\text { - pO2 }<72 \mathrm{mmHg} \\
\text { - oxygen saturation }<90 \% \\
\text { - pCO2 }>46 \mathrm{mmHg} \\
\text { - reduced Horovitz-Quotient :PaO2/FiO } 2<200 \mathrm{mmHg}\end{array}$ \\
\hline cardiac & $\begin{array}{l}\text { - BP systolic }<90 \mathrm{mmHg}(\text { or }<30 \mathrm{mmHg} \text { to prior } \mathrm{BP}) \\
\text { - Cardiac index }<2.1 \mathrm{ml} / \mathrm{min} / \mathrm{m}^{\wedge} 2 \\
\text { Echocardiography: } \\
\text { - LVEF }<30 \% \\
\text { - high cardiac filling pressure }(\mathrm{PCWP}>16 \mathrm{mmHg} \text { or/and RAP }>12 \mathrm{mmHg}) \\
\text { Laboratory: } \\
\text { - BNP }>100 \mathrm{pg} / \mathrm{ml}\end{array}$ \\
\hline DIC & $\begin{array}{l}\text { Laboratory abnormalities: } \\
\text { - prolonged INR }(>1) / \text { aPTT }(>36 \mathrm{sec}) \\
\text { - decrease in the platelet count }\left(<100^{\circ} 000 / \mu \mathrm{l}\right) \\
\text { - decrease in fibrinogen }(<100 \mathrm{mg} / \mathrm{dl}) \\
\text { - increase of d-dimer }(>500 \mu \mathrm{g} / \mathrm{l})\end{array}$ \\
\hline CNS & Glasgow coma scale $<15$ points \\
\hline colitis & $\begin{array}{l}\text { Ultrasound examination or X-ray: } \\
\text { - thickening small bowel }>3 \mathrm{~mm} / \text { colonic wall }>2-5 \mathrm{~mm} \\
\text { - dilation of the intestinal loops }\end{array}$ \\
\hline paralytic ileus & Clinically are no rumors heard for over three minutes, or flatus or stool are absent \\
\hline bleeding & $\begin{array}{l}\text { Symptoms: } \\
\text { - hypotension }>100 / 60 \mathrm{mmHg} \\
\text { - heart rate }<100 \text { per minute } \\
\text { - or disturbance of consciousness } \\
\text { - melena } \\
\text { Ultrasound: } \\
\text { - free liquid } \\
\text { Laboratory: } \\
\text { - erythrocytes: men }<4,8-5,9 \mathrm{Mio} . / \mu \mathrm{l} \text {; women }<4,3-5,2 \mathrm{Mio} . / \mu \mathrm{l} \\
\text { - hemoglobin concentration: men }<13-18 \mathrm{~g} / \mathrm{dl} \text {; women: }<12-16 \mathrm{~g} / \mathrm{dl}\end{array}$ \\
\hline hepatic & $\begin{array}{l}\text { laboratory: } \\
\text { - INR }>1.5 \\
\text { - total bilirubin }>2 \mathrm{mg} / \mathrm{dl} \\
\text { - serum creatinine }>1.4 \mathrm{mg} / \mathrm{dl} \\
\text { - serum albumin }<3.5 \mathrm{~g} / \mathrm{dl} \\
\text { Sonography: } \\
\text { ascites }\end{array}$ \\
\hline
\end{tabular}

BP: blood pressure; qSOFA: quick sepsis-related organ failure assessment score; $\mathrm{pO} 2$ oxygen partial pressure; $\mathrm{pCO}$ : carbon dioxide partial pressure; LVEF: left ventricle ejection fraction; PCWP: pulmonary capillary wedge pressure; RAP: right atrial pressure; BNP: brain natriuretic peptide; peak; DIC: disseminated intravascular coagulation; INR: international normalized ratio; aPTT: activated Partial Thromboplastin Time; CNS: central nervous system. 